\title{
GROWTH PERFORMANCE, HORMONAL DYNAMICS AND INTESTINAL MICROARCHITECTURE IN BROILERS FED $\beta$-GALACTO-OLIGOSACCHARIDES DURING CYCLIC COLD STRESS
}

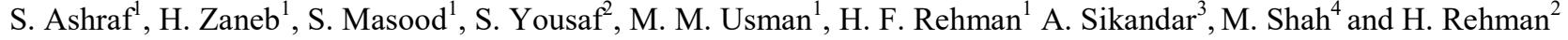 \\ ${ }^{1}$ Department of Anatomy and Histology, ${ }^{2}$ Department of Physiology, University of Veterinary and Animal Sciences, 54000, \\ Lahore, Pakistan; ${ }^{3}$ Department of Anatomy and Histology, Sub-campus, Jhang, University of Veterinary and Animal Sciences- \\ Lahore (UVAS), 35200, Pakistan; ${ }^{4}$ Department of animal health, University of Agriculture Peshawar, Pakistan. \\ ${ }^{\#}$ Corresponding Author's email: hafsa.zaneb@uvas.edu.pk
}

\begin{abstract}
Day-old chicks $(\mathrm{n}=125)$ in 5 groups were raised under standard management till $21^{\text {st }}$ day. From $22^{\text {nd }}-35^{\text {th }}$ day, control (TN) group received $26^{\circ} \mathrm{C}$ whereas four groups were exposed to cyclic cold stress (CS) $\left(15^{\circ} \mathrm{C} \pm 2^{\circ} \mathrm{C}\right.$ for 8 hours/day). The COLD (control cold-stressed) and TN groups received corn-based diet (CBD) whereas CS+0.1\% $\beta-\mathrm{GOS}, \mathrm{CS}+0.2 \% \beta$ GOS and CS $+0.5 \% \beta$-GOS groups, received CBD supplemented with $\beta$-GOS $(0.1 \%, 0.2 \%$ and $0.5 \%$, respectively). Results demonstrated that cold-exposed birds were presented with poor feed efficiency (FE), reduced body weights (BW), relative weights (RW) of ceca, intestinal villus surface area (VSA) and duodenal intraepithel ial lymphocyte count (IELs) compared with TN group. COLD group also had higher serum cortisol and triiodothyronine, RW of heart and liver and acidic goblet cells (AGCs) in small intestine when compared with TN group. Dietary supplementation of $\beta$ GOS (0.5\%) improved FE, RW of ceca and duodenal AGCs whereas reduced serum cortisol and jejunal IELs when compared with COLD group. Moreover, all dietary inclusions of $\beta$-GOS $(0.1 \%, 0.2 \%$ and $0.5 \%)$ also enhanced intestinal VSA and jejunal AGCs when compared with COLD group. In conclusion, dietary $\beta$-GOS helped to improve growth performance and serum cortisol along with modulating the intestinal microarchitecture and acidic mucin production in broilers during CS.
\end{abstract}

Keywords: $\beta$-Galacto-oligosaccharides, cortisol, growth performance, intestinal morphometry, broiler.

\section{INTRODUCTION}

Poultry industry has undergone substantial expansion during last few decades. Tremendous development in the fields of genetics, nutrition and management has helped the producer to maximize feed efficiency, and in turn, economic gains. Nevertheless, with an increase in performance, sensitivity of the bird also increased tremendously particularly towards the heat and cold (Burkholder et al., 2008). Although most of the poultry is raised in environmentally-controlled sheds however, maintaining the thermal comfort zone (TCZ) for optimum growth is quite costly (Yang et al., 2014). During the growth phase, TCZ of broilers has a narrow range of $18-22^{\circ} \mathrm{C}$. However, when environmental temperature touches the lower limit of TCZ i.e. $18^{\circ} \mathrm{C}$, broiler suffers from cold stress (CS) (Aarif et al., 2013).

Cold-exposed broilers typically exhibit poor growth performance inspite of an increased feed consumption (Ipek and Sahan, 2006). Apart from production losses, exposure to cold also results in impairment of various physical activities, permanent tissue damage and ultimately death especially in young chicks (Zhang et al., 2011). Exposure to the CS activates hypothalamic-pituitary-thyroid axis (HPT) of the bird and increases corticosterone and cortisol (Aarif et al., 2013; Slota et al., 2015). Growing body of evidence suggest that the corticosterone is a common link between stress, immunosuppression and infections in animals (Borsoi et al., 2015). CS also initiates energy driven processes in various organs, induces hypoxia and production of reactive oxygen species. Gastrointestinal tract of the broiler appears one of the most vulnerable organs during this cold-induced oxidative stress (Fu et al., 2012). Moreover, CS also effectuates intestinal microbial dysbiosis and attachment of enteropathogens to the intestinal mucosa (Borsoi et al., 2015). Microbial dysbiosis and inflammatory cytokines during CS results in enteritis and increases the corticosterone, which further suggests the role of CS in hyper activation of HPT axis and intestinal infections. Breach in intestinal integrity of the cold-exposed broiler may also result in translocation of pathogens to systemic circulation and generalized infections.

Over the years, low doses of antibiotic growth promoters (AGPs) have been added in poultry feed for compensating the growth losses during CS (Huff et al., 2015). However, with an increase in concerns regarding the safety of animal products, there use in animal feed 
was prohibited in 2006 (EC Regulation No. 1831/2003). But their complete exclusion from livestock feed not only increased the incidences of clinical infections but also the use of therapeutic antibiotics. These circumstances led to an understanding that alternative strategies are required to be in place if AGPs have to be removed from livestock feed so that optimal production targets could be achieved under stressful situations. Among such alternatives the most widely studied agents include probiotics and prebiotics (Alloui et al., 2013).

The prebiotics are non-digestible oligosaccharides which competitively enrich the innate microbial ecosystem of the host. The inulin and galactooligosaccharide (GOS) are the most commonly used prebiotics in humans and animals (Huyghebaert et al.,2011). The structure of $\beta$-GOS resembles human milk oligosaccharides and is often added to formula milk to improve the gut health of infants (Bruno-Barcena and Azcarate-Peril, 2015). Lacto-bifidogenic property of the $\beta$-GOS is the basis for the improvement effectuated in gastrointestinal health, structure and immune function both in humans and animals (Vulevic et al., 2008; Zhong et al., 2009; Searle et al. 2010; Vendrig et al. 2013; Bhatia et al. 2015; Bruno-Barcena and Azcarate-Peril, 2015; Varasteh et al., 2015). Nevertheless, $\beta$-GOS originating from the Bifidobacterium galactosidase failed to improve the performance of broilers during thermoneutral situations but it has been suggested that the effect of the prebiotics on performance of broiler are variable (Biggs at al., 2007). The dietary $\beta$-GOS has been utilized in poultry during heat stress (Varasteh et al., 2015) however little is known regarding its utility during cold stress particularly with respect to its influence on growth performance and intestinal microarchitecture and immune components in broilers. Therefore, keeping in mind the whole scenario and pressing need to seek the alternatives of AGPs present study was planned with an aim to elucidate the role of different dietary inclusions of $\beta$-GOS originating from Lactobacillus reuteri L103 galactosidase on growth performance, selected hormonal profile, organ development, intestinal microarchitecture, intraepithelial lymphocyte counts and mucin dynamics in broilers during cyclic cold stress.

\section{MATERIALS AND METHODS}

Animal Trial: The plan of this trail was approved by Directorate of Advanced Studies, University of Veterinary and Animal Sciences Lahorevide notification No. DAS/517 and all the experimental procedures were performed in accordance with the ethical standards established by Ethical Review Committee for the Use of Laboratory Animals. The experiment included day-old Hubbard chicks $(n=125)$ which were procured from a commercial hatchery. Upon arrival, chicks were weighed and placed in room covered with wood shaving litter. The birds were randomly allotted to five treatment groups $(\mathrm{N}$ $=25)$ with five replications in each group $(n=5)$. Brooding temperature and relative humidity during the first week was $35^{\circ} \pm 2^{\circ} \mathrm{C}$ and $65 \pm 5 \%$, respectively. Every week $3{ }^{\circ} \mathrm{C}$ reduction in temperature was done to achieve $26^{\circ} \mathrm{C}$ on day 21 . From $22^{\text {nd }}$ day onwards birds in control (TN) group continued to receive standard temperature of $26^{\circ} \mathrm{C}$ till the end of experiment and remaining four groups were exposed to a to a cyclic temperature treatment of $15^{\circ} \pm 2^{\circ} \mathrm{C}$ for eight hours in night and $26^{\circ} \mathrm{C}$ for remaining period till conclusion of study i.e. 35 days.

During the whole experimental period, birds in $\mathrm{TN}$ and control cold stress (COLD) group received cornbased diet (CBD) and CS+0.1\% $\beta$-GOS, CS+0.2\% $\beta-G O S$ and $\mathrm{CS}+0.5 \% \beta-\mathrm{GOS}$ groups received CBD supplemented with different dietary levels of $\beta$-GOS $(0.1 \%, 0.2 \%$ or $0.5 \%$ ), respectively. Birds were given free access to feed and water and all the diets were formulated without antimicrobials and coccidiostats according to NRC (1994) recommendations (Table 1). Birds were vaccinated intraocularly by live attenuated Newcastle disease vaccine (Ceva-Phylaxia, Budapest, Hungary) on day 1, with a booster on day 20 in drinking water. Similarly, vaccination against Infectious Bronchitis Disease (Lohman Animal Health GmbH, Cuxhaven, Germany) was done by intraocular route on day 8 and repeated on day 20 in drinking water.

Preparation of $\boldsymbol{\beta}$-Galacto-Oligosaccharides: The $\beta$ GOS mixture was prepared by the Department of Food Science and Human Nutrition, University of Veterinary and Animal Sciences Lahore. It was synthesized using $\beta$ galactosidases from Lactobacillus reuteri L103 employing lactose as a substrate. Resultant mixture of $\beta$ GOS, had degree of polymerization of $2-3$, contained $\sim 80 \%$ of $\beta-(1 \rightarrow 6)$ and $\sim 9 \% \quad \beta-(1 \rightarrow 3)$ linked transgalactosylation products of the total GOS formed whereas $\beta-(1 \rightarrow 4)$-linked products could not be detected. The main components of GOS mixtures were $\beta$-D-Galp$(1 \rightarrow 3)-D-G l c, \quad \beta$-D-Galp- $(1 \rightarrow 6)-D-G l c, \quad \beta$-D-Galp$(1 \rightarrow 3)-D-G a l, \quad \beta$-D-Galp- $(1 \rightarrow 6)-D-G a l, \quad \beta$-D-Galp$(1 \rightarrow 6)-D-L a c \quad\left(6^{\circ}-\mathrm{GL}\right)$ and $\beta$-D-Galp- $(1 \rightarrow 3)-\mathrm{D}-\mathrm{Lac}\left(3^{\prime}-\right.$ GL) of $\beta-(1 \rightarrow 6)$ and $\beta-(1 \rightarrow 3)$ glycoside linkages in their transgalactosylation products. When the galactosidase from the Lactobacillus reuteri L103 is utilized for GOS production, $\beta-(1 \rightarrow 6)$ linked products constitute $60 \%$ of the total linkages formed during the reaction.

Growth Performance: Growth performance of the broiler was measured in terms of feed consumption (FC), body weight $(\mathrm{BW})$ and feed efficiency $(\mathrm{FE})$. Data for the FC was obtained on daily basis, by deducting the feed offered from the feed left in feeders whereas that of BW was taken on weekly basis. Weekly FE was calculated utilizing the data of FC and BW. 
Sampling Protocols: At the end of trial, 10 birds from each treatment group ( 2 birds/ replicate) were killed by severing their jugular vein. Blood samples and viscera were collected for further analysis. Visceral organs including liver, pancreas, spleen, heart, bursa, gizzard, ceca and small intestine were collected and weighed. Absolute weight of these viscera was used for calculating the relative visceral weight (RVW).

Serum Cortisol, Triiodothyronine (T3) and Thyroxine (T4) estimation: The collected blood samples were allowed to stand for 4 hours and centrifuged at $1500 \times \mathrm{g}$ at $4^{\circ} \mathrm{C}$ for 20 minutes. Harvested serum samples were used for the estimation of thyroid hormones, $\mathrm{T} 3(\mathrm{ng} / \mathrm{mL}$; Jei Daniel Biotech Corp. Shandong, China) T4 ( $\mu \mathrm{g} / \mathrm{dL}$; Jei Daniel Biotech Corp. Shandong, China), and cortisol ( $\mu \mathrm{g} / \mathrm{dL}$; Monobind Inc., Lake Forest, CA, USA), with the help of commercial kits using competitive enzyme linked immune-sorbent assay (ELISA).

Intestinal Microarchitecture: For morphometric analysis, two cm segments of the small intestine (middle part of the duodenum, jejunum and ileum) were collected and flushed with normal saline to remove the intestinal contents. Samples were preserved in $10 \%$ neutral buffered formalin for tissue processing by paraffin embedding technique. Briefly, segments after flushing with normal saline were preserved using $10 \%$ neutral buffered formalin, dehydrated in ascending concentrations of alcohols (70\%-100\%), cleared (xylene), infiltrated (molten wax at $56{ }^{\circ} \mathrm{C}$ ) and embedded in paraffin wax to obtain a block of wax with tissue (Bancroft et al. 2013). From each sample, $4 \mu \mathrm{m}$ serial sections were taken with microtome (AMOS Scientific AEM-450, Australia) on three separate frosted slides. Slides were either stained with standard hematoxylin and eosin (H\&E) staining technique or combined alcian blueperiodic acid Schiff (AB-PAS) method according to the protocol described by Bancroft et al., (2013). Tissue sections for morphometric analysis were observed with light microscope (Labomed, Lx 400 U.S.A) at 4x magnification fitted with digital imaging system.

Morphometry of the small intestine was performed on H\&E stained sections. Ten well-structured villus crypts were selected on the basis of intact lamina propria as described previously (Ashraf et al., 2013). Measurements for villus height (VH) was recorded from tip of villus to its junction with crypt, villus width (VW), was measured at its widest part, whereas crypt depth (CD) was taken from base of the crypt to its interface with the villus base. The VH:CD was also calculated. The villus surface area (VSA) was calculated using the formula $(2 \pi)(\mathrm{VW} / 2)(\mathrm{VH})$ as described earlier (Ashraf et al., 2013)

Intraepithelial Lymphocyte Count: H\&E stained sections from duodenum, jejunum and ileum were also observed for counting IELs in ten intact villi previously selected for morphometric assessments. Avian IELs are rounded cells with spherical nuclei. They are differentiated from nuclei of enterocytes on the basis of nuclear morphology. Nuclei of the enterocytes are oval whereas the nuclei of the IELs are spherical (Ashraf et al., 2013).

Goblet cells: Small intestinal sections stained by combined AB-PAS technique were observed for counting the goblet cells containing acidic mucins (AGCs). The AGCs appeared blue under the light microscope and were counted in ten intact villi.

Statistical Analysis: Data were analysed by using SPSS 13.0 (SPSS Inc., Chicago, IL, USA). Data were subjected to Kolmogrov Smirnov test for checking its normal distribution. After confirmation, data were analysed using one-way analysis of variance (ANOVA) and Duncan's multiple range test. Significance level was set at $(\mathrm{P} \leq 0.05)$.

\section{RESULTS}

Growth Performance: Data of the weekly growth performance indicated that during the first week birds receiving the diet supplemented with $\beta$-GOS consumed more $(\mathrm{P} \leq 0.05)$ feed and gained lesser $(\mathrm{P} \leq 0.05)$ weight and therefore were presented with poor FE when compared with the TN group. During cold exposure the COLD group had increased $(\mathrm{P} \leq 0.05) \mathrm{FC}$ and decreased $(\mathrm{P} \leq 0.05) \mathrm{BW}$ and $\mathrm{FE}$ when compared with the TN group. Compared with the COLD, supplementation of $\beta$-GOS improved $(\mathrm{P} \leq 0.05) \mathrm{BW}$ and reduced $(\mathrm{P} \leq 0.05) \mathrm{FC}$ and numerical value of $\mathrm{FE}$ in all the $\beta$-GOS supplemented groups during last week. However pre-CS level of BW and $\mathrm{FE}$ was attained only in $\mathrm{CS}+0.5 \% \beta-\mathrm{GOS}$ group (Table 2).

Organ Development: Data regarding the RVW of the broiler revealed that the exposure to the CS increased $(\mathrm{P} \leq 0.05)$ the $\mathrm{RW}$ of liver, heart and spleen, whereas decreased $(\mathrm{P} \leq 0.05)$ the $\mathrm{RW}$ of ceca in the COLD compared with the TN group. Compared with COLD, supplementation of $\beta$-GOS improved $(\mathrm{P} \leq 0.05)$ the RW of ceca in $\mathrm{CS}+0.5 \% \beta$-GOS without attaining its pre-CS levels, whereas RW of other viscera remained unaffected by $\beta$-GOS supplementation (Table 3 ).

Serum Cortisol, Triiodothyronine (T3) and Thyroxine (T4): Serum determination of the cortisol and thyroid hormone revealed that the cold-exposed broilers had increased $(\mathrm{P} \leq 0.05)$ serum concentrations of cortisol and $\mathrm{T} 3$ in the COLD when compared with the TN group. Compared with the COLD, supplementation of $\beta$-GOS lowered $(\mathrm{P} \leq 0.05)$ the serum concentration of cortisol in all $\beta$-GOS supplemented groups and serum T3 in 
CS $+0.5 \% \beta$-GOS group. Supplemented groups did not attain the pre-CS levels of cortisol and T3. Serum concentration of $\mathrm{T} 4$ remained unchanged in all the experimental groups (Table 4).

Intestinal microarchitecture: Data from the morphometric analysis of the small intestine indicated that the CS reduced $(\mathrm{P} \leq 0.05)$ the VSA of duodenum, jejunum and ileum in COLD when compared with the TN group. Similarly, COLD group was also presented with decreased $(\mathrm{P} \leq 0.05) \mathrm{VH}, \mathrm{VW}$ and $\mathrm{VH}: \mathrm{CD}$ and increased $\mathrm{CD}$ in all segments of the small intestine when compared with the TN group. Compared with the COLD group, supplementation of $\beta$-GOS improved $(\mathrm{P} \leq 0.05)$ all morphometric parameters in the duodenum, jejunum and ileum in all the $\beta$-GOS supplemented groups. Improvement in VSA of the supplemented groups in duodenum exceeded pre-CS levels, whereas in ileum the VSA was comparable with TNZ group. In jejunum supplementation however did not restore the pre-CS level of morphometric assessments (Table 5).

Intraepithelial Lymphocyte Count: Results from the counting of intestinal IELs revealed decrease $(\mathrm{P} \leq 0.05)$ in their number in duodenum and increase $(\mathrm{P} \leq 0.05)$ in jejunum of the COLD when compared with the TN group. Compared with the COLD group, supplementation of $\beta$-GOS increased $(\mathrm{P} \leq 0.05)$ the count of IELs in duodenum of all the $\beta$-GOS supplemented groups. In jejunum and ileum IEL count decreased $(\mathrm{P} \leq 0.05)$ in $\beta$ GOS receiving groups when compared with the COLD group (Table 6).

Goblet Cells: Results from the counting of the AGCs in intestine revealed an increase $(\mathrm{P} \leq 0.05)$ in their count in jejunum and ileum whereas duodenal AGCs decreased $(\mathrm{P} \leq 0.05)$ in the COLD compared with the TN group. Compared with the COLD group, supplementation of $\beta$ GOS increased $(\mathrm{P} \leq 0.05)$ the count of AGCs in duodenum in all $\beta$-GOS supplemented groups whereas in jejunum in $\mathrm{CS}+0.1 \% \beta$-GOS, CS $+0.2 \% \beta$-GOS groups. However, in ileum supplementation of $\beta$-GOS did not influence the

count of AGCs when compared with the COLD group (Table 7).

Table 1. Control diet composition and calculated analysis.

\begin{tabular}{lcc}
\hline Ingredient (g/kg) & Starter phase & $\begin{array}{c}\text { Grower } \\
\text { phase }\end{array}$ \\
\hline Corn & 401.5 & 575.7 \\
Rice broken & 150 & -- \\
Soy meal & 115.4 & 96 \\
Sunflower meal & 120 & 130 \\
Canola meal & 90 & 50 \\
Rapeseed meal & 50 & 76 \\
Rice polish & --- & 40 \\
Guar meal & 10 & --- \\
Wheat bran & 13.4 & --- \\
Molasses & 20 & --- \\
Sodium bicarbonate & 0.3 & 0.65 \\
Sodium chloride & 2.1 & 2.1 \\
Di-calcium phosphate & 13.3 & 14.9 \\
L-Lysine & 3 & 3.5 \\
DL-Methionine & 1 & 1.2 \\
Vit-mineral premix $*$ & 10 & 10 \\
Nutrient composition & & \\
Calculated ME (kcal.kg) & 2750 & 2850 \\
CP & 196 & 185 \\
DM & 870 & 880 \\
Crude fibre & 60.5 & 63.5 \\
Crude fat & 21.6 & 23.5 \\
Total ash & 57.7 & 54 \\
\hline Vitamin mineral premix (each kg contained ): ascorbic acid, \\
26000 IU ; retinol, 200,000 IU; cholecalciferol, $80,000 \mathrm{IU} ;$ \\
tocopherol, 1072 IU; thiamine, 11666 IU ; pyridoxine, 33333 \\
IU; menadione, 11,333 IU; riboflavin, 54,000 IU ; niacin, \\
5,36,000 IU; folic acid, 13600 IU; methylcobalamin, 223 IU; \\
biotin, 1340 IU; Ca, 195 g; K, 70 g; Na, 18 g; Mg, 6 g; Fe, \\
2,000 mg; Zn, 1,200 mg; Mn, 1,200 mg; Cu, 400 mg; I, 40 mg, \\
Co, 20 mg and Se, 8 mg ME: metabolizable energy; CP: crude \\
protein; DM: Dry Matter & & \\
& &
\end{tabular}

Table 2. Influence of cold stress and $\beta$-GOS supplementation on growth performance in broilers.

\begin{tabular}{|c|c|c|c|c|c|c|c|c|}
\hline \multirow[b]{2}{*}{ Parameter } & \multicolumn{7}{|c|}{ Treatments $^{* *}$} & \multirow[b]{2}{*}{$\begin{array}{c}\text { Pooled } \\
\text { SEM }\end{array}$} \\
\hline & Week & $\mathbf{T N}$ & COLD & CS+0.1\%ß-GOS & CS+0.2\% $\%-G O S$ & CS $+0.5 \% \beta-G O S$ & $\begin{array}{c}P- \\
\text { value }\end{array}$ & \\
\hline \multirow{5}{*}{$\mathrm{FC}^{\#}(\mathrm{~g})$} & $1^{\text {st }}$ & $156^{b}$ & $152^{b}$ & $167^{\mathrm{a}}$ & $168^{\mathrm{a}}$ & $167^{\mathrm{a}}$ & 0.03 & 4 \\
\hline & $2^{\text {nd }}$ & 368 & 362 & 366 & 358 & 369 & 0.63 & 5 \\
\hline & $3^{\text {rd }}$ & 915 & 938 & 932 & 930 & 931 & 0.10 & 5 \\
\hline & $4^{\text {th }}$ & $1300^{\mathrm{b}}$ & $1624^{\mathrm{a}}$ & $1646^{\mathrm{a}}$ & $1657^{\mathrm{a}}$ & $1563^{\mathrm{a}}$ & $\leq 0.001$ & 49 \\
\hline & $5^{\text {th }}$ & $2405^{\mathrm{c}}$ & $2714^{\mathrm{a}}$ & $2639^{\mathrm{ab}}$ & $2581^{\mathrm{b}}$ & $2604^{\mathrm{b}}$ & $\leq 0.001$ & 47 \\
\hline \multirow{4}{*}{$\mathrm{BW}^{\# \#}(\mathrm{~g})$} & $1^{\text {st }}$ & $142^{\mathrm{a}}$ & $137^{\mathrm{ab}}$ & $134^{\mathrm{b}}$ & $136^{\mathrm{ab}}$ & $130^{\mathrm{b}}$ & 0.01 & 2 \\
\hline & $2^{\text {nd }}$ & 472 & 474 & 477 & 480 & 489 & 0.22 & 5 \\
\hline & $3^{\text {rd }}$ & 947 & 920 & 940 & 942 & 941 & 0.20 & 7 \\
\hline & $4^{\text {th }}$ & $1373^{\mathrm{a}}$ & $1221^{\mathrm{b}}$ & $1440^{\mathrm{a}}$ & $1443^{\mathrm{a}}$ & $1459^{\mathrm{a}}$ & $\leq 0.001$ & 11 \\
\hline
\end{tabular}




\begin{tabular}{|c|c|c|c|c|c|c|c|c|}
\hline \multirow{6}{*}{$\mathrm{FE}^{\# \# \#}$} & $5^{\text {th }}$ & $2380^{\mathrm{a}}$ & $1717^{\mathrm{d}}$ & $2166^{b c}$ & $2110^{c}$ & $2343^{\mathrm{ab}}$ & $\leq 0.001$ & 49 \\
\hline & $1^{\text {st }}$ & $1.1^{\mathrm{b}}$ & $1.09^{\mathrm{b}}$ & $1.3^{\mathrm{a}}$ & $1.2^{\mathrm{a}}$ & $1.3^{\mathrm{a}}$ & $\leq 0.001$ & 0.03 \\
\hline & $2^{\text {nd }}$ & 0.78 & 0.76 & 0.79 & 0.72 & 0.76 & 0.32 & 0.02 \\
\hline & $3^{\text {rd }}$ & 0.96 & 1.02 & 1.0 & 1.01 & 1.0 & 0.08 & 0.08 \\
\hline & $4^{\text {th }}$ & $0.94^{\mathrm{c}}$ & $1.3^{\mathrm{a}}$ & $1.12^{\mathrm{b}}$ & $1.14^{\mathrm{b}}$ & $1.10^{\mathrm{b}}$ & $\leq 0.001$ & 0.04 \\
\hline & $5^{\text {th }}$ & $1.02^{\mathrm{c}}$ & $1.60^{\mathrm{a}}$ & $1.24^{\mathrm{b}}$ & $1.22^{\mathrm{b}}$ & $1.10^{\mathrm{c}}$ & $\leq 0.001$ & 0.03 \\
\hline
\end{tabular}

${ }^{\mathrm{a}-\mathrm{d}}$ Means within a row with different superscripts differ significantly $(\mathrm{P} \leq 0.05)$

Values represent means of five replicates

*TN, Control group; COLD, cold stress control group; CS $+0.1 \% \beta-G O S(0.1 \% \beta-G O S$ supplemented cold stressed group); CS $+0.2 \% \beta-$ GOS $(0.2 \% \beta$-GOS supplemented cold stressed group) and CS $+0.5 \% \beta-G O S(0.5 \% \beta$-GOS supplemented cold stressed group). ${ }^{\#}$ Feed consumption, ${ }^{\# \#}$ body weight, ${ }^{\# \# \#}$ feed efficiency

Table 3. Influence of cold stress and $\beta$-GOS supplementation on relative weights of viscera in broilers.

\begin{tabular}{|c|c|c|c|c|c|c|c|}
\hline \multirow{2}{*}{ Organ } & \multicolumn{7}{|c|}{ Treatments $^{*}$} \\
\hline & TN & COLD & CS+0.1\% $\%$-GOS & CS+0.2\%及-GOS & CS+0.5\% $\%$-GOS & P-value & Pooled SEM \\
\hline Liver & $1.96^{\mathrm{b}}$ & $2.6^{\mathrm{a}}$ & $2.6^{\mathrm{a}}$ & $2.6^{\mathrm{a}}$ & $2.4^{\mathrm{a}}$ & $\leq 0.001$ & 0.06 \\
\hline Spleen & $0.07^{\mathrm{b}}$ & $0.1^{\mathrm{a}}$ & $0.1^{\mathrm{a}}$ & $0.1^{\mathrm{a}}$ & $0.1^{\mathrm{a}}$ & 0.01 & 0.00 \\
\hline Gizzard & 2.50 & 2.0 & 2.0 & 1.7 & 2.0 & 0.06 & 0.120 \\
\hline Pancreas & 0.18 & 0.2 & 0.1 & 0.2 & 0.1 & 0.14 & 0.004 \\
\hline Heart & $0.34^{b}$ & $0.6^{\mathrm{a}}$ & $0.7^{\mathrm{a}}$ & $0.6^{\mathrm{a}}$ & $0.6^{\mathrm{a}}$ & $\leq 0.001$ & 0.006 \\
\hline Bursa & 0.19 & 0.18 & 0.17 & 0.17 & 0.17 & 0.06 & 0.010 \\
\hline Small Intestine & 3 & 2.87 & 2.90 & 2.89 & 3.1 & 0.07 & 0.160 \\
\hline Caecum & 0.77 & $0.55^{\mathrm{b}}$ & $0.6^{\mathrm{ab}}$ & $0.70^{\mathrm{ab}}$ & $0.75^{\mathrm{a}}$ & $\leq 0.001$ & 0.152 \\
\hline
\end{tabular}

${ }^{\mathrm{a}-\mathrm{b}}$ Means within a row with different superscripts differ significantly $(\mathrm{P} \leq 0.05)$

Values represent means of five replicates

*see the footnotes of Table 2

Table 4. Influence of cold stress and $\beta$-GOS supplementation on serum T3, T4 and cortisol in broilers.

\begin{tabular}{lccccccc}
\hline \multirow{2}{*}{ Parameter } & \multicolumn{9}{c}{ Treatments } & Pooled \\
\cline { 2 - 7 } & TN & COLD & CS+0.1\% $\%$-GOS & CS+0.2\% $\%$-GOS & CS+0.5\% $\%$-GOS & P-value & SEM \\
\hline Cortisol $(\mathrm{ng} / \mathrm{mL})$ & $1.0^{\mathrm{d}}$ & $1.9^{\mathrm{a}}$ & $1.6^{\mathrm{b}}$ & $1.4^{\mathrm{c}}$ & $1.5^{\mathrm{c}}$ & $\leq 0.001$ & 0.04 \\
$\mathrm{~T} 4(\mu \mathrm{g} / \mathrm{dL})$ & 3.59 & 3.68 & 3.66 & 3.69 & 3.58 & 0.9 & 0.05 \\
$\mathrm{~T} 3(\mathrm{ng} / \mathrm{mL})$ & $3.10^{\mathrm{b}}$ & $3.41^{\mathrm{a}}$ & $3.27^{\mathrm{ab}}$ & $3.28^{\mathrm{ab}}$ & $3.20^{\mathrm{ab}}$ & 0.01 & 0.04 \\
\hline
\end{tabular}

${ }^{\mathrm{a}-\mathrm{c}}$ Means within a row with different superscripts differ significantly $(\mathrm{P} \leq 0.05)$

Values represent means of five replicates

"see the footnotes of Table 2

Table 5. Influence of cold stress and $\beta$-GOS supplementation on intestinal microarchitecture in broilers.

\begin{tabular}{|c|c|c|c|c|c|c|c|c|}
\hline \multirow[b]{2}{*}{$\begin{array}{l}\text { Intestinal } \\
\text { segments }\end{array}$} & \multirow[b]{2}{*}{ Parameters } & \multicolumn{7}{|c|}{ Treatments" } \\
\hline & & TN & COLD & $\begin{array}{c}\text { CS+0.1\% } \\
\beta-G O S\end{array}$ & $\begin{array}{c}\text { CS+0.2\% } \beta- \\
\text { GOS }\end{array}$ & $\begin{array}{c}\text { CS+0.5\% } \\
\beta-G O S\end{array}$ & $\begin{array}{c}\text { P- } \\
\text { value }\end{array}$ & $\begin{array}{l}\text { Pooled } \\
\text { SEM }\end{array}$ \\
\hline \multirow{5}{*}{ Duodenum } & Villus height $(\mu \mathrm{m})$ & $893.7^{\mathrm{c}}$ & $678.3^{\mathrm{d}}$ & $1028.4^{\mathrm{b}}$ & $1024.9^{b}$ & $1137.3^{\mathrm{a}}$ & $\leq 0.001$ & 24 \\
\hline & Villus width $(\mu \mathrm{m})$ & $136.2^{\mathrm{c}}$ & $100.6^{\mathrm{d}}$ & $209.3^{\mathrm{a}}$ & $165.8^{\mathrm{b}}$ & $141.7^{\mathrm{c}}$ & $\leq 0.001$ & 6 \\
\hline & Crypt depth $(\mu \mathrm{m})$ & $108.1^{\mathrm{c}}$ & $188.7^{\mathrm{a}}$ & $174.1^{\mathrm{ab}}$ & $154^{\mathrm{ab}}$ & $148.8^{\mathrm{b}}$ & $\leq 0.001$ & 6.37 \\
\hline & $\mathrm{VH}: \mathrm{CD}$ & $6.4^{\mathrm{bc}}$ & $5.10^{\mathrm{c}}$ & $6.2^{\mathrm{bc}}$ & $6.85^{\mathrm{ab}}$ & $7.8^{\mathrm{a}}$ & 0.004 & 0.23 \\
\hline & $\begin{array}{l}\text { Villus surface } \\
\text { area }(\mu \mathrm{m})^{3}\end{array}$ & $121323^{c}$ & $67871^{\mathrm{d}}$ & $214592^{\mathrm{a}}$ & $170260^{\mathrm{b}}$ & $161244^{\mathrm{b}}$ & $\leq 0.001$ & 77474 \\
\hline \multirow{5}{*}{ Jejunum } & Villus height $(\mu \mathrm{m})$ & $983.1^{\mathrm{a}}$ & $770^{\mathrm{b}}$ & $864.0^{\mathrm{c}}$ & $917.5^{\mathrm{b}}$ & $935.3^{\mathrm{b}}$ & $\leq 0.001$ & 11 \\
\hline & Villus width $(\mu \mathrm{m})$ & $203.4^{\mathrm{a}}$ & $102.8^{\mathrm{b}}$ & $85.4^{\mathrm{c}}$ & $95.8^{\mathrm{bc}}$ & $98.6^{\mathrm{b}}$ & $\leq 0.001$ & 3 \\
\hline & Crypt depth $(\mu \mathrm{m})$ & $106.5^{\mathrm{c}}$ & $144.3^{\mathrm{a}}$ & $131.3^{\mathrm{b}}$ & $140.7^{\mathrm{a}}$ & $146.2^{\mathrm{a}}$ & $\leq 0.001$ & 2 \\
\hline & $\mathrm{VH}: \mathrm{CD}$ & $7.2^{\mathrm{a}}$ & $6.9^{\mathrm{ab}}$ & $6.5^{\mathrm{bc}}$ & $6.5^{\mathrm{bc}}$ & $6.4^{\mathrm{c}}$ & $\leq 0.001$ & 0.12 \\
\hline & $\begin{array}{l}\text { Villus surface } \\
\operatorname{area}(\mu \mathrm{m})^{3}\end{array}$ & $629738.9^{\mathrm{a}}$ & $248231.9^{\mathrm{cd}}$ & $231782.8^{d}$ & $275924.2^{\mathrm{bc}}$ & $289711.9^{b}$ & $\leq 0.001$ & 82041 \\
\hline \multirow{2}{*}{ Ileum } & Villus height $(\mu \mathrm{m})$ & $859^{\mathrm{ab}}$ & $540.7^{\mathrm{c}}$ & $831.2^{\mathrm{b}}$ & $860.2^{\mathrm{ab}}$ & $882.8^{\mathrm{a}}$ & $\leq 0.001$ & 19 \\
\hline & Villus width $(\mu \mathrm{m})$ & $51^{\mathrm{c}}$ & $45.5^{\mathrm{d}}$ & $76.9^{\mathrm{b}}$ & $87.7^{\mathrm{a}}$ & $75.1^{\mathrm{b}}$ & $\leq 0.001$ & 1 \\
\hline
\end{tabular}




$\begin{array}{cccccccc}\text { Crypt depth }(\mu \mathrm{m}) & 81^{\mathrm{b}} & 147^{\mathrm{a}} & 76^{\mathrm{b}} & 76^{\mathrm{b}} & 84^{\mathrm{b}} & \leq 0.001 & 3 \\ \text { VH }: \text { CD } & 6.7^{\mathrm{b}} & 6.2^{\mathrm{b}} & 10.8^{\mathrm{a}} & 11^{\mathrm{a}} & 10.5^{\mathrm{a}} & \leq 0.001 & 0.20 \\ \text { Villus surface } & 137168^{\mathrm{c}} & 77435^{\mathrm{d}} & 200680^{\mathrm{b}} & 237023^{\mathrm{a}} & 208155^{\mathrm{b}} & \leq 0.001 & 34870 \\ \text { area }(\mu \mathrm{m})^{3} & & & & & & & \end{array}$

$\mathrm{VH}=$ Villus height; $\mathrm{VW}=$ Villus width; $\mathrm{VSA}=$ villus surface Area; $\mathrm{CD}=\mathrm{Crypt}$ Depth; $\mathrm{VH}: \mathrm{CD}=\mathrm{Villus}$ height: crypt depth ratio. Values represent means of five replicates

${ }^{\mathrm{a}-\mathrm{c}}$ Means within a row with different superscripts differ significantly $(\mathrm{P} \leq 0.05)$, "see the footnotes of Table 2

Table 6. Influence of cold stress and $\beta$-GOS supplementation on intraepithelial lymphocyte count in small intestine of broilers.

\begin{tabular}{|c|c|c|c|c|c|c|c|}
\hline \multirow{2}{*}{$\begin{array}{c}\text { Intestinal } \\
\text { Segment }\end{array}$} & \multicolumn{6}{|c|}{ Treatments $^{*}$} & \multirow{2}{*}{$\begin{array}{c}\text { Pooled } \\
\text { SEM }\end{array}$} \\
\hline & TN & COLD & $\mathrm{CS}+0.1 \beta-\mathrm{GOS}$ & CS+0.2\% $\beta-G O S$ & CS+0.5\% $\beta-G O S$ & P-value & \\
\hline Duodenum & $67^{\mathrm{a}}$ & $27^{\mathrm{d}}$ & $37^{\mathrm{c}}$ & $37^{\mathrm{c}}$ & $46^{b}$ & $\leq 0.001$ & 2.07 \\
\hline Jejunum & $68^{\mathrm{b}}$ & $80^{\mathrm{a}}$ & $32^{\mathrm{d}}$ & $44^{\mathrm{c}}$ & $27^{\mathrm{d}}$ & $\leq 0.001$ & 3.27 \\
\hline Ileum & $71^{\mathrm{a}}$ & $88^{\mathrm{a}}$ & $79^{\mathrm{a}}$ & $31^{\mathrm{b}}$ & $79^{\mathrm{a}}$ & $\leq 0.001$ & 3.77 \\
\hline
\end{tabular}

${ }^{\mathrm{a}-\mathrm{d}}$ Means within a row with different superscripts differ significantly $(\mathrm{P} \leq 0.05)$

Values represent means of five replicates

*see the footnotes of Table 2

Table 7. Influence of cold stress and $\beta$-GOS supplementation on number of acidic goblet cells in small intestine of broilers.

\begin{tabular}{|c|c|c|c|c|c|c|c|}
\hline \multirow{2}{*}{ Parameters } & \multicolumn{6}{|c|}{ Treatments $^{*}$} & \multirow{2}{*}{$\begin{array}{c}\text { Pooled } \\
\text { SEM }\end{array}$} \\
\hline & TN & COLD & 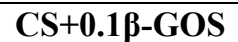 & CS+0.2\%及-GOS & CS+0.5\% $\beta-G O S$ & P-value & \\
\hline Duodenum & $65^{\mathrm{d}}$ & $93.5^{\mathrm{c}}$ & $112^{\mathrm{b}}$ & $112^{b}$ & $120^{\mathrm{a}}$ & $\leq 0.001$ & 2.96 \\
\hline Jejunum & $102^{\mathrm{c}}$ & $113^{\mathrm{b}}$ & $139^{\mathrm{a}}$ & $136^{\mathrm{a}}$ & $76^{c}$ & $\leq 0.001$ & 3.67 \\
\hline Ileum & $106^{\mathrm{b}}$ & $146^{\mathrm{a}}$ & $140^{\mathrm{a}}$ & $141^{\mathrm{a}}$ & $142^{\mathrm{a}}$ & $\leq 0.001$ & 3.15 \\
\hline
\end{tabular}

${ }^{\mathrm{a}-\mathrm{d}}$ Means within a row with different superscripts differ significantly $(\mathrm{P} \leq 0.05)$

Values represent means of five replicates

*see the footnotes of Table 2

\section{DISCUSSION}

In broiler rearing, heat stress has always been a point of concern for the producers but considerable data reveals that the cold stress is equally detrimental for the health and welfare of poultry (Phuong et al., 2016). After the ban on the use of AGPs in poultry feed the scientist started seeking safer alternatives which can diminish the effects of these stressors. Present study demonstrates the influence of $\beta$-GOS preparations originating from Lactobacillus reuteri $\mathrm{L} 103$ on growth performance, organ development, selected hormonal indices, intestinal microarchitecture, IELs and mucin dynamics in broiler during cyclic cold stress.

Results of the present study revealed that the cold-exposed birds consumed more feed but were unable to gain weight and were, therefore, presented with poor FE. Regarding the effects of CS on growth performance our findings reiterated the findings of previous reports in broilers (Ipek and Sahan, 2006; Blahova et al., 2007; Yang et al., 2014). Greater FC of the cold-exposed broilers may be a result of increased metabolic rate resulting from hyper activation of HPT axis. However, this additional feed consumed by the broiler is utilized for thermogenesis (Ipek and Sahan, 2006), therefore, excess nutrients are not available for improving the BW and FE. All the dietary inclusions of $\beta$-GOS improved the BW and numerically reduced the value of FE in cold-exposed broilers, with only $0.5 \% \beta$-GOS supplementation achieving the performance level of the control group. Recently, Huff et al. (2015) indicated that supplementation of prebiotic proved beneficial in improving the $\mathrm{BW}$ and feed conversion ratio of the Escherichia coli-challenged broilers during the cold exposure. Similarly, Yousaf et al. (2016) also reported that supplementation of $\beta$-GOS improved the BW of broiler during thermoneutral situations. We utilized the $\beta$ GOS originating from L.reuteri L103 in our study whose specific mechanism of action has not been studied so far. However, the improvement in the performance of coldexposed broiler in response to $\beta$-GOS may be ascribed to the improved intestinal microarchitecture resulting in better digestibility and availability of nutrients (Bhatia et al., 2015; Bruno-Barcenaand Azcarate-Peril, 2015; Varasteh et al., 2015; Yousaf et al.,2016). Moreover, the prebiotic might have influenced the activity of hypothalamic pituitary adrenal axis (HPA) (Sohail et al.,2010). These aforementioned alterations may be traced in our study therefore a positive relation may be 
assumed to exist between the growth performance, intestinal microarchitecture and hormonal level.

Results of the organ development indicated that the CS exposure increased the RW of heart and liver whereas decreased the RW of caecum in broilers. Comparable effects of CS on the weight of right ventricle of heart and liver has been observed earlier (Ipek and Sahan, 2006). Ventricular hypertrophy as a result of coldinduced hypoxia (Ipek and Sahan, 2006), increase in lipogenesis and lipid accumulation in tissues (Puvadolpirod and Thaxton, 2000) might have contributed to the increase in weight of these viscera's. Reduction in the RW of ceca during the CS might have resulted from the intestinal damage (Tsiouris et al., 2015). The RW of bursa of Fabricius, spleen gizzard and small intestine remained unaffected during the cold treatment. Contrary to our results, Guimaraes et al., (2001) reported suppressive effects of CS on the growth and development of bursa of Fabricius in broilers. Lack of any influence of CS on these viscera including immune organs during the current scenario may be difficult to explain. However, it has been suggested earlier that the reactive mechanisms of the CS in broiler are quite complicated and variable. Stress modifiers like duration, frequency, magnitude and temporal relation between sampling and stress application might be some of the factors responsible for these differences. Therefore, the inconsistencies between the results of various studies may seem highly plausible (Zhang et al., 2011; Quinteiro-Filho et al., 2015). Supplementing the diet of the cold-exposed broiler with $\beta$-GOS remained ineffective in neutralizing the negative effects of CS on the RW of heart and liver. However, $0.5 \% \quad \beta$-GOS supplementation reversed the effects of $\mathrm{CS}$ on RW of ceca. The improvement observed in the cecal RW may be attributed to the proposed improvement of the indigenous microbial community in large intestine in response to feeding prebiotics during CS (Huff et al., 2015).

Results of the serum analysis indicated that the cold-exposed broilers had elevated serum cortisol and T3 hormones whereas serum T4 remained unaffected by the cold treatment. Previous studies have suggested the variable effect of $\mathrm{CS}$ on the corticosterone and cortisol ranging from an increase (Arif et al., 2013; Borsoi et al., 2015) decrease (Hangalapura et al., 2004) and no effect at all (Mills et al.,1997). Similarly, findings from the various studies regarding the effects of the CS on the thyroid hormones (T3 and T4) are also inconsistent (Hangalapura et al., 2004; Blahova et al., 2007, Aarif et al.,2013; Bahadoran and Hassazadeh, 2010). Virtually all the animal or human studies involving any kind of stress agree that it activates the HPA and HPT axis with a change in hormonal dynamics. Stress response is, however, a complex process controlled by multiple factors like norepinephrine and interleukins (IL) etc. in addition to adrenal and thyroid hormones (Borsoi et al.,
2015). Moreover, response of the stress also varies with stress modifiers like duration, severity, type and genetics of animal. Hence a different hormonal outcome of the CS in different studies is highly possible (Tsiouris et al., 2015). Activation of HPA axis might have led to increased level of the hormones in our study whereas increase in serum T3 might be due to the increased conversion of $\mathrm{T} 4$ in to $\mathrm{T} 3$ as it is a temperature-driven process (Hangalapura et al., 2004). Increase in FC of the cold-exposed broiler may reflect a change in T3 dynamics during current study. All the dietary inclusions of $\beta$-GOS improved the cortisol and T3 hormone in coldexposed supplemented groups. Influence of the prebiotics on the activity of HPA axis during thermoneutral (Chen et al., 2009) or heat stress situations in pigs and broilers has already been reported (Sohail et al., 2010; Haldar et al., 2011). At present it is not clear that how the $\beta$-GOS influenced the activity of the HPA axis but it has been suggested earlier that the prebiotics influence the activity of this axis via an increase in probiotic organism (Sohail et al., 2010).

Results of the histomorphometric analysis of small intestine indicated that the cold exposure proved detrimental for the small intestinal mucosa. Cold exposure decreased the $\mathrm{VH}$ and increased the $\mathrm{CD}$ in all of its segments. Comparable effects of the CS on the morphology of small intestine in broiler have been reported by Slota et al. (2015). Small intestine of the broiler serves as a major digestive and absorptive site and $\mathrm{VH}$ and VSA are important determinant of this intestinal activity. On the other hand, $\mathrm{CD}$ and $\mathrm{VH}: \mathrm{CD}$ provides valuable information regarding the cellular turnover at the villous surface. It has been observed that the CS induces oxidative damage in small intestine along with altering its immune function. These changes promote microbial dysbiosis and increases the attachment of pathogens e.g. Salmonella spp. etc (Fu et al., 2013; Borsoi et al., 2015; Tsiouris et al., 2015). These changes might have led to the shortening of $\mathrm{VH}$ and increase in turn over at the villus tip might have contributed to the greater CD in the current situations. Supplementation of $\beta$-GOS proved beneficial for the micro architectural components of small intestine during CS. During the heat stress improvement in the morphometric characteristics of broiler's intestine in response to prebiotics in general and $\beta$-GOS in specific has been reported earlier (Ashraf et al., 2013; Song et al., 2014; Varasteh et al., 2015). The improvement observed in current situation may be ascribed to the multiple factors which have been published by various studies utilizing the $\beta$-GOS. These include improvement in integrity of intestinal barrier and immune function, increase in production of short chain fatty acids, reduction in intestinal $\mathrm{pH}$ and suppression of enteropathogens in response to dietary $\beta$-GOS (Searle et al., 2010; Varasteh et al., 2015). Additionally, prebiotics have also been reported to increase the vasculogenesis of 
the villus which promotes the cellular mitosis (Haldar et al., 2011).

Quantification of the intestinal IELs revealed variable effects of cold stress in different segments of small intestine. Cold exposure decreased the count of IELs in duodenum and increased them in jejunum without affecting the count of IELs in ileum. IELs are important effector components of the gut associated lymphoid tissue (Ashraf et al., 2013). Little is known regarding the effects of $\mathrm{CS}$ on the quantitative or qualitative aspects of IELs in broiler gut. However, recently Borsoi et al. (2015) indicated that the CS is immunosuppressive as it resulted in a decrease in peripheral T-lymphocytes and inflammatory cytokines in broilers and rats. Apart from the CS, a decrease in the count of intestinal IELs in response to the restraint stress in the mice has also been published by Jarillo-Luna (2008). Furthermore, Zhang et al. (2005) reported a decrease in release of IFN- $\gamma$ from the IELs of gut in response to electric foot shock in rats. Contrary to these findings, Hangalapura et al. (2003) reported a stimulation of cellular immunity in response to the cold exposure in broilers. Decrease in the count of duodenal IELs in the current study may be correlated with increased circulating cortisol as a result of HPA axis activation. Glucocorticoids are immunosuppressive and inhibit the production of pro-inflammatory cytokines like (IL)-12 and (TNF)- $\alpha$, along with stimulation of the release of anti-inflammatory cytokines (IL)-4 and (IL)-10 (Sternberg and Licinio, 1995). Like the CS dietary inclusion of $\beta$-GOS produced variable effects on different intestinal segments with neutralizing the changes in count produced by the CS. Parallel to the influence of stress review of literature also revealed variable effects of prebiotics on the immune system ranging from immune stimulation (Gaskins et al., 1996; Schley and Field, 2002) to immune suppression (Janardhana et al., 2009). Similarly difference in the susceptibility and responsiveness of various segments of small intestine towards heat stress and supplementation of $\beta$-GOS have been reported by Varasteh et al., (2015) and was attributed to the difference in microbial composition of different segments. Dietary $\beta$-GOS has an ability to produce both the pro- and anti-inflammatory cytokines (Searle et al., 2010) but the exact mechanism governing the production of different cytokines (pro- and antiinflammatory) and the predominant effects of only one type in one segment still needs further elucidation.

Results from the AGCs count revealed an increase in their number as a result of cold exposure in all segments of small intestine. Goblet cells containing acidicmucins are an important component of the intestinal barrier. They play an important role in preventing the attachment of enteropathogens to intestinal mucosa. Increase in the count of AGCs during stress is in agreement with previous studies and can be a protective response of intestinal mucosa against intestinal microbial dysbiosis during CS (Soderholm and Perdue, 2001). The $\beta$-GOS $0.1 \%$ and $0.2 \%$ dietary inclusion further enhanced the count of AGCs in duodenum and jejunum whereas $0.5 \%$ dietary inclusion only increased it in duodenum. We did not observe any effect of supplementation on the count of AGCs in ileum. Increase in the count of GCs with supplementation of various pre- and probiotics has been reported previously (Baurhoo et al., 2007; Ashraf et al., 2013). Recently Bhatia et al. (2015) reported an increase in the expression of mucin gene (MUC2) in human adenocarcinoma-derived cells in response to GOS in vitro. Exact mechanism governing the increase of AGCs in the proximal segments compared to distal ones is not understood fully, however, increase in the AGCs in duodenum and jejunum might be associated with up regulation of the mucin genes, acceleration of their differentiation, and immunostimulatory properties of the prebiotic agents (Baurhoo et al., 2007; Bhatia et al., 2015). However, it still needs to be clarified that whether this increase is a direct effect of the $\beta-G O S$ or is an indirect effect of probable eubiosis resulting from prebiotic supplementation.

In conclusion, results of the present study indicated that dietary supplementation of the $0.5 \% \beta$ GOS proved useful in mitigating the influences of cold stress on growth performance of broiler. The improvement in the performance of the broiler was coupled with improvement in intestinal microarchitecture and reduction in circulating cortisol. Moreover, dietary $\beta$ GOS also influenced the goblet cell dynamics and produced immunomodulation in gut. However further trails are warranted to elucidate the mechanism by which the $\beta$-GOS produced its effects.

Acknowledgements: This work was sponsored by Higher Education Commission, Pakistan.

\section{REFERENCES}

Aarif, O., S. Mahapatra, M.A. Yatoo, and S.A. Dar (2013). Impact of cold stress on physiological, hormonal and immune status in male and female broad breasted white turkeys. J. Stress. Physio. Biochem. 9: 54-60.

Alloui, M.N., W.Szczurek, andS. Swiatkiewicz (2013). The usefulness of prebiotics and probiotics in modern poultry nutrition: a review. Ann Anim. Sci. 13: 17-32.

Ashraf, S., H. Zaneb, M.S. Yousaf, A. Ijaz, M.U. Sohail, S. Muti, M.M. Usman, S. Ijaz, and H. Rehman (2013). Effect of dietary supplementation of prebiotics and probiotics on intestinal microarchitecture in broilers reared under cyclic heat stress. J. Anim. Physiol. Anim. Nutr. 97: 6873. 
Bahadarona, S., and M. Hassenzadeh (2010). Effect of early cold exposure on the endocrine responses of broiler chickens and the incidence of ascites syndrome. Iran J. Vet. Med. 4: 11-16.

Bancroft, J.D., A.D. Floyd, and S.K. Suvarna (2013). Bancroft's Theory and practice of histological techniques. 7th ed. New York (NY) USA: Elsevier Health Sci.

Baurhoo, B.L., Phillip, and C.A. Ruiz-Feria (2007). Effect of purified lignin and mannanoligosaccharide on salmonella colonization of the chicken intestine. Poult. Sci. 70: 2433-2438.

Bhatia, S., N.P. Prabhu, C.A. Benefiel, M.J. Milller, J. Chow, S.R. Davis, and H. Rex-gaskins (2015). Galactooligosaccharides may directly enhance intestinal barrier function through the modulation of goblet cells. Mol. Nutr. Food Res. 59: 566-573.

Blahova, J., R. Dobsikova, Strakova, and E. Suchy (2007). Effect of low environmental temperature on performance and blood system in broiler chickens (Gallus domesticus). Acta. Vet. Brno. 76: 17-23.

Biggs P, Parsons C, Fahey, GC. 2007. The effects of several oligosaccharides on growth performance, nutrient digestibilities, and cecal microbial populations in young chicks. Poult. Sci. 86(11): 2327-2336.

Borsoi, A., A.S. Calefi, A.J.P. Ferreira, and C.S. AstolfiFerreira (2015). Effects of cold stress and Salmonella Heidelberg infection on bacterial load and immunity of chickens. Avian. Pathol. 44: 490-497.

Bruno-Barcena, J.M., and M.A. Azcarate-Peril (2015). Galacto-oligosaccharides and colorectal cancer. Feeding our Intestinal Probiome. J. Funct. Food. 12: $92-108$.

Burkholder, K.M., K.L. Thompson, M.E. Einstein, T.J. Applegate, and J.A. Patterson (2008). Influence of stressors on normal intestinal microbiota, intestinal morphology, and susceptibility to salmonella enteritidis colonization in broilers. Poult. Sci. 87: 1734-1741.

Chen, Y.J., I.H. Kim, J.H. Cho, J.S. Yoo, Y. Wang, Y. Huang, H.J. Kim, and S.O. Shin (2009). Effects of chitooligosaccharide supplementation on growth performance, nutrient digestibility, blood characteristics and immune responses after lipopolysaccharide challenge in weanling pigs. Livest. Sci. 124: 255-260.

Fu, J., C.P. Liu, Z.W. Zhang, W. Liao, and S.W. Xu (2012). Effects of acute and chronic cold stress on expression of cyclooxygenase- 2 and prostaglandin e synthase mrna in quail intestine. Pak Vet. J. 33: 358-363.

Gaskins, H.R., R.I. Mackie, T. May, and K.A. Garleb, K.A (1996). Dietaryfructo-oligosaccharide modulates large intestinal inflammatoryresponses to
Clostridium difficile in antibiotic-compromised mice. Microb. Ecol. Health Dis. 9: 157-166.

Guimarães, E.B., A.C. Vasconcelos, N.R.S. Martins, and L. Moro (2001). Porcentagem de parênquima e índiceapoptótico da bolsacloacalemfrangos de corteemambiente de conforto e estressetérmico. Arq. Bras. Med. Veta.Zootec. 55:178-186.

Haldar, S., T.K. Ghosh, Toshiwati, and M.R. Bedford (2011). Effects of yeast (Saccharomyces cervisiae) and yeast protein concentrate on production performance of broiler chickens exposed to heat stress and challenged with Salmonella enteritidis. Anim. Feed. Sci. Technol. 169, 61-71.

Hangalapura, B.N., M.G.B. Nieuwland, G. Vries Reilingh, M.J.W. Heetkamp, H. Van-den-Brand, B. Kemp, and H.K. Parmentier (2003). Effects of cold stress on immune responses and body weight of chicken lines divergently selected for antibody responses to sheep red blood cells. Poult. Sci. 82: $1692-$ 1700 .

Hangalapura, B.N., Nieuwland, B.G.M., Buyse, J., Kemp, B., andParmentier, H.K., 2004. Effect of duration of cold stress on plasma adrenal and thyroid hormone levels and immune responses in chicken lines divergently selected for antibody responses. Poult Sci. 83: 1644-1649.

Huff, G.R., W.E. Huff, N.C.Rath, F.A. El-Gohary, Z.Y. Zhou, and S. Shini (2015). Efficacy of a novel prebiotic and a commercial probiotic in reducing mortality and production losses due to cold stress and Escherichia coli challenge of broiler chicks. Poult. Sci. 94: 918-926.

Huyghebaert, G., R. Ducatelle, andF. Van-Immerseel (2011). An update on alternatives to antimicrobial growth promoters for broilers. Vet. J. 187: 182188.

Ipek, A., and U. Sahan (2006). Effects of cold stress on broiler performance and ascites susceptibility.Anim Sci. 19: 734-738.

Janardhana, V., M.M. Broadway, M.P. Bruce, J.W. Lowenthal, M.S. Geier, R. H. Hughes, A.G.D. Bean (2009). Prebiotics modulate immune responses in gut-associated lymphoid tissue of chickens. J.Nutr. 139: 1404-1409.

Jarillo-Luna, A.,V. Rivera-Aguilar, B.E. Martı'nezCarrillo, E. Barbosa-Cabrera, H.R. Garfias, and R. Campos-Rodri'guez (2008).Effect of restraint stress on the population of intestinal intraepithelial lymphocytes in mice. Brain. Behav. Immun. 22: 265-275.

Mills, P.J., M.G. Ziegler, T. Patterson, J.E. Dimsdale, R. Hauger, M. Irwin, and I. Grant (1997). Plasma catecholamine and lymphocyte beta 2 -adrenergic receptor alterations in elderly Alzheimer 
caregivers under stress. Psychosom. Med. 59: 251-256.

Council NR. 1994. Nutrient Requirements of Poultry Nith Revised Edition National Academy Press. Washington DC.

Phuong, H.N., E. Greene, A. Donoghue, G. Huff, F.D. Clark, and S. Dridi (2016). A new insight into cold stress in poultry production. Adv. Food Technol. Nutr. Sci Open J. 2: 1-2.

Puvadolpirod, S., and J.P. Thaxton (2000). Model of Physiological Stress in Chickens Response parameters. Poult. Sci. 79: 363-369.

Quinteiro-Filho, W.M, M.V. Rodrigues, A. Ribeiro, V. Ferraz-de-Paula, M.L. Pinheiro, L.R.M. Sa, A.J.P. Ferreira, and J Palermo-Neto (2015). Acute heat stress impairs performance parameters and induces mild intestinal enteritis in broiler chickens: Role of acute hypothalamic-pituitaryadrenal axis activation. J. Anim. Sci. 90: 19861994.

Schley, P.D., and C.J. Field (2002). The immuneenhancing effects of dietary fibres and prebiotics. Brit J.Nutr. 87: 221-230.

Searle, L.E.J., W.A Cooley, G. Jones, A. Nunez, B. Crudgington, U. Weyer, A.H. Dugdale, G. Tzortzis, J. W. Collins, M.J. Woodward and R.M.L. Ragione (2010). Purified galactooligosaccharide, derived from a mixture produced by the enzymic activity of Bifidobacteriumbifidum, reduces Salmonella entericaserovar Typhimurium adhesion and invasion in vitro and in vivo. J. Med. Microbio. 159: 1428-1439.

Slota, C., A. Chi, G. Chen, M. Bevans, and N.P. Weng (2015). Norepinephrine preferentially modulates memory CD8 $\mathrm{T}$ cell function inducing inflammatory cytokine production and reducing proliferationin response to activation. Brain Behav. Immun. 46: 168-179.

Sohail, M.U., A. Ijaz, M.S. Yousaf, K. Ashraf, H. Zaneb, M. Aleem, and H. Rehman (2010). Alleviation of cyclic heat stress in broilers by dietary supplementation of mannanoligosaccharide and Lactobacillus based probiotic: dynamics of cortisol, thyroid hormones, cholestrol, C-reactive protein and humoral. Poult. Sci. 89: 1934-1938.

Soderholm, J.D., and M.H. Perdue (2001). Stress and intestinal barrier function. Am. J. Physiol. Gastrointest. Liver Physiol. 280: 7-13.

Song, J., K. Xiao, X.L. Ke, L.F. Jiao, C.H. Hu, Q.Y. Diao, B. Shi, and X.T. Zou (2014). Effect of a probiotic mixture on intestinal microflora, morphology, and barrier integrity of broilers subjected to heat stress. Poult. Sci. 93: 581-588.
Sternberg, E.M., and J. licinio (1995). Overview of Neuroimmune stress interactions. Ann N Y Acad Sci. 771: 363-371.

Tsiouris, V.I., C. Georgopoulou, Batzios, R. Pappaioannou, Ducatelle, and P. Fortomaris (2015). High stocking density as a predisposing factor for necrotic enteritis in broiler chicks. Avian. Pathol. 44: 59-66.

Varasteh, S., S. Braber, P. Akbari, J. Garssen, and J.F. Gremmels (2015). Differences in susceptibility to heat stress along the chicken intestine and the protective effects of galacto-oligosaccharides. PLoS ONE. 10: 1-18.

Vendrig, J.C., L.E. Coffeng, and J. Fink-Gremmels (2013). In vitro evaluation of defined oligosaccharide fractions in an equine model of inflammation. BMC Vet. Res. 9: 147-157.

Vulevic, J., A. Drakoularakou, P. Yaqoob, G. Tzortzis and G.R. Gibson (2008). Modulation of the fecal microflora profile and immune function by a novel trans-galactooligosaccharide mixture (BGOS) in healthy elderly volunteers. Am J. Clin. Nutr. 88: 1438-46.

Yang, X., Y.H. Luo, Q.F. Zeng, K.Y. Zhang, X.M. Ding, S.P. Bai, and J. Wang (2014). Effects of low ambient temperatures and dietary vitamin $\mathrm{C}$ supplement on growth performance, blood parameters, and antioxidant capacity of 21-dayold broilers. Poult. Sci. 93: 898-905.

Yousaf, M.S., A. Ijaz, K. Ashraf, M.A. Rashid, A. Hafeez, H. Zaneb, E. Dar, R. Naseer, I. Rabbani, J. Zentek and Rehman (2016). Comparative effects of different dietary concentrations of $\beta$-galactooligosaccharides on growth performance, feed conversion efficiency and organs development in broilers. J. Anim. Plant. Sci. 26: 1603-1608.

Zhang, X., M. Okutsu, O. Kanemi, and R. Nagatomi (2005). Effect of foot shock stress on the interferon-gamma production of murine intestinal intraepithelial lymphocytes. Immunol. Lett. 100: 170-176.

Zhang, Z.W., Z.H. Lv, J.L. Li, S. Li, S.W. Xu, and X.L. Wang (2011). Efficacy of a novel prebiotic and a commercial probiotic in reducing mortality and production losses due to cold stress and Escherichia coli challenge of broiler chicks. Poult. Sci. 90: 1555-1561.

Zhong, Y., D. Cai, W. Cai, S. Geng, L. Chen, and T. Han (2009). Protective effect of galactooligosaccharide-supplemented enteral nutrition on intestinal barrier function in rats with severe acute pancreatitis. Clin. Nutr. 28: 575-580. 